Behavioural pharmacology

\title{
Central injection of L- and D-aspartate attenuates isolation-induced stress behavior in chicks possibly through different mechanisms
}

\author{
Edi Erwan ${ }^{a}$, Vishwajit Sur Chowdhury ${ }^{b}$, Mao Nagasawa ${ }^{a}$, Ryosei Goda ${ }^{a}$, Tsuyoshi Otsuka a , \\ Shinobu Yasuo ${ }^{\mathrm{a}}$, Mitsuhiro Furuse ${ }^{\mathrm{a}, *}$ \\ a Laboratory of Regulation in Metabolism and Behavior, Graduate School of Bioresource and Bioenvironmental Sciences, Kyushu University, \\ Fukuoka 812-8581, Japan \\ ${ }^{\mathrm{b}}$ Division for Arts and Science, Faculty of Arts and Science, Kyushu University, Fukuoka 819-0395, Japan
}

\section{A R T I C L E I N F O}

\section{Article history:}

Received 5 March 2014

Received in revised form

2 April 2014

Accepted 15 April 2014

Available online 9 May 2014

Keywords:

Intracerebroventricular

L-Aspartate

D-Aspartate

NMDA receptor

Chick

\begin{abstract}
A B S T R A C T
Intracerebroventricular (i.c.v.) injection of L- and D-aspartate (L- and D-Asp) has been shown to have a sedative effect with and without a hypnotic effect, respectively, in neonatal chicks experiencing isolation stress. However, the mechanisms of the different stress-attenuating functions of L- and D-Asp have not yet been fully clarified. In the present study, we investigated the involvement of the $N$-methyl- $D$ aspartate (NMDA) receptor in order to reveal the receptor-mediated function of L- and D-Asp. To reveal whether L-and D-Asp act through the NMDA receptor, (+)-MK-801, which is an antagonist of NMDA receptors, was used in the current study. In experiment 1 , the chicks were injected i.c.v. with either saline, (+)-MK-801, L-Asp or L-Asp plus (+)-MK-801. The sedative and hypnotic effects induced by L-Asp were blocked by co-administration with $(+)-\mathrm{MK}-801$. In experiment 2 , the chicks were injected $\mathrm{i}$. c.v. with either saline, (+)-MK-801, D-Asp or D-Asp plus (+ )-MK-801. Importantly, the sedative effects induced by D-Asp were shifted to hypnotic effects by co-administration with $(+)-\mathrm{MK}-801$. Taken together, L-Asp could induce sedative and hypnotic effects for stress behaviors through the NMDA receptor, but the attenuation of stress behaviors by D-Asp might be via simultaneous involvement of other receptors besides the NMDA receptor in this process. These differences may explain the different functional mechanisms of L- and D-Asp in the central nervous system.
\end{abstract}

(c) 2014 Elsevier B.V. All rights reserved.

\section{Introduction}

It is well established that excitatory amino acids (EAAs), L-glutamate (L-Glu) and L-aspartate (L-Asp) occur as neurotransmitters in the chicken brain to act on the EAA receptors in the central nervous system (CNS) (Balázs et al., 2012). These amino acids can induce powerful stimulatory effects in the CNS (Matthews et al., 1991). Most excitatory neurotransmission in the brain is mediated by glutamate receptors, which are divided into two groups: ionotropic and metabotropic glutamate receptors. There are three classes of ionotropic receptor: $N$-methyl- $D$-aspartate (NMDA); $\alpha$-amino-3-hydroxy-5-methyl-4-isoxazole propionic acid (AMPA); and kainate (Cotman and Monaghan, 1989).

In previous studies it was shown that intracerebroventricular (i.c.v.) administration of some L-amino acids caused sedative and hypnotic effects through specific receptors under acutely stressful conditions. For instance, L-proline (L-Pro) induced sedative and

\footnotetext{
* Corresponding author. Tel.: +81 92642 2953; fax: +8192642 2954

E-mail address: furuse@brs.kyushu-u.ac.jp (M. Furuse).
}

hypnotic effects through the NMDA receptor (Hamasu et al., 2010), but L-serine (Shigemi et al., 2008) and L-ornithine (Kurata et al., 2011) acted through the $\gamma$-aminobutyric acid (GABA) A receptor. The NMDA receptor is widely distributed in the CNS including the hypothalamus (Halpain et al., 1984) and pituitary (Halpain et al., 1984; Lindstrom and Ohlsson, 1992), suggesting its involvement in the neurotransmission process in the brain. It has been suggested that in chicks, L-Asp may function through the NMDA receptor (Chen et al., 2005) as a selective NMDA receptor agonist (Kubrusly et al., 1998). Recently, it was reported that i.c.v. administration of (+)-MK-801, an NMDA receptor antagonist, stimulated distress vocalizations (DVs) and active wakefulness and decreased sitting or standing time in chicks treated with i.c.v. L-Pro (Hamasu et al., 2010).

D-Asp, a metabolite of L-Asp, is also present in the nervous tissues of chickens (Neidle and Dunlop, 1990). Although there have been a considerable number of investigations into the function of D-Asp regarding its role in the endocrine system (D'Aniello, 2007), in food intake (Koyuncuoğlu et al., 1982; Erwan et al., 2013a,b) and in thermoregulation (Koyuncuoğlu and Berkman, 1982), there has been less exploration of its role as a possible neurotransmitter. 
Both L- and D-Asp induced sedative effects under an acutely stressful condition. However, L-Asp, but not D-Asp, increased the time spent in a sleeping posture (Erwan et al., 2012).

Using neonatal chicks, Feltenstein et al. (2003) investigated the behaviors induced by social-isolation stress. When chicks are isolated, they express characteristic stress-related behaviors which include increased DVs, active wakefulness, and a decrease in sleeping behavior (Yamane et al., 2009b). These stressful behavioral parameters were taken as a standard against which to assess the anxiolytic activity of several amino acids (Shigemi et al., 2008; Kurata et al., 2011; Erwan et al., 2012). Therefore, observation of these behaviors resulting from isolation stress together with L-and D-Asp treatments can be useful for estimating the anti-anxiety effects of these amino acids.

We looked at all these findings together, to clarify the difference in function between L- and D-Asp in terms of decreasing stress behavior, and hypothesized that the NMDA receptor may be involved in the stress-attenuating process which could be identified in chicks by using the NMDA receptor antagonist, (+)-MK-801.

\section{Material and methods}

\subsection{Animals and drugs}

One-day-old layer chicks were purchased from a local hatchery (Murata hatchery, Fukuoka, Japan) and housed in a wire-meshed cage $\left(50 \times 35 \times 33 \mathrm{~cm}^{3}\right)$ in a group (20-25 birds) at a constant temperature of $30 \pm 1^{\circ} \mathrm{C}$ and with continuous light until the experimental day. Chicks were all of the same age and were housed without an adult. Food (AX, Toyohashi Feed and Mills Co. Ltd., Aichi, Japan) and water were available ad libitum. On the day of the experiment, chicks (5-6 days old) were assigned to treatment groups on the basis of their body weight in order to produce uniform treatment groups. The number of animals used in each group was kept to the minimum that would still ensure adequate statistical power. This study was performed according to the Guidance for animal experiments in the faculty of agriculture and in the graduate course of Kyushu University and Law No. 105 and Notification No. 6 of the government. L- and D-Asp were purchased from Wako Pure Chemical Industries (Osaka, Japan). The NMDA receptor antagonist (+)-MK-801 maleate was purchased from Tocris Bioscience (Ellisville, USA). The drugs were dissolved in a vehicle of $0.85 \%$ saline containing 0.1\% Evans Blue (Wako Pure Chemical Industries, Ltd., Osaka, Japan).

\subsection{Procedure for behavioral test}

Drugs were injected intracerebroventricularly (i.c.v.) by microsyringe into the left lateral ventricle of the chicks in a $10-\mu$ l dose, using the method of Davis et al. (1979). Minimal stress and pain are experienced when this method is used, as described elsewhere (Koutoku et al., 2005). Each chick received a single injection in line with any one of the treatments described below. As for the dose, in the current study, based on our previous report (Erwan et al., 2012), we decided to use $1.68 \mu \mathrm{mol}$ of L- or D-Asp to analyze the mechanism of attenuating stress responses. Recently, we reported that of different doses of L- and D-Asp $(0.42,0.84$ or $1.68 \mu \mathrm{mol})$, only the highest dose completely attenuated the responsiveness of chicks experiencing isolation-induced stress compared with the control. Although the low and medium doses showed a dose-dependent tendency of declining stress behavior, no significant effect was found (Erwan et al., 2012). In Experiment 1, chicks were administered either vehicle saline, $(+)-\mathrm{MK}-801$ maleate $(0.50 \mathrm{nmol})$, L-Asp $(1.68 \mu \mathrm{mol})$ or L-Asp $(1.68 \mu \mathrm{mol})$ plus $(+)-\mathrm{MK}-801$ maleate
$(0.50 \mathrm{nmol})$. Experiment 2 was similar to experiment 1 except LAsp was replaced with D-Asp. The dosage of (+)-MK-801 was based on that specified in a previous study (Hamasu et al., 2010). After injection, chicks were immediately placed in a monitoring cage $(40 \mathrm{~cm} \times 30 \mathrm{~cm} \times 20 \mathrm{~cm}$ acrylic glass) with paper (changed for each animal) on the floor. Video cameras were positioned to record on digital versatile disc (DVD) the behavior of chicks from three different directions. The postures recorded during a 10-min period were characterized as (1) active wakefulness; (2) standing/sitting motionless with eyes open; (3) standing motionless with eyes closed; and (4) sitting motionless with head drooped (sleeping posture). The sedative effect was evaluated by categories (1), (2), and (3), whereas the hypnotic effect was evaluated by category (4) (Suenaga et al., 2008). It was found in young adult hens that with both the sleeping posture (head tucked under a wing) and the resting posture with eyes closed, electrophysiological sleep nearly always occurred (van Luijtelaar et al., 1987). The time each chick spent in each posture was determined by watching the DVDs. During the monitoring period, chicks were deprived of water and food. DVs of the chicks were simultaneously recorded and counted using Gretchen software (Excla Inc., Japan), and suppression of DVs was judged as a sedative effect. Data were collected each second for the 10 -min period. The monitoring systems were in a separate room to avoid disturbing the animals. At the end of the experiments, the birds were decapitated following anesthesia with isoflurane (Mylan Inc., Japan).

\subsection{Statistical analysis}

In all the experiments, data were statistically analyzed by a randomized two-way analysis of variance (ANOVA), and the Tukey-Kramer test was done as a post hoc test when a significant interaction was detected. Significant differences implied $P<0.05$. Values are presented as means \pm S.E.M. Statistical analysis was conducted using a commercially available package, StatView (version 5, SAS Institute, Cary, USA, 1998). All data were first subjected to a Thompson rejection test to eliminate outliers $(P<0.01)$, and the data that remained were used in the analysis among groups.

\section{Results}

\subsection{Effects of $(+)-M K-801$ on sedative and hypnotic behaviors induced by $L-A s p$}

Fig. 1 shows the effects of i.c.v. injection of L-Asp with or without $(+)-M K-801$ on the number of DVs, a measure of social separation stress, for 10 min post injection. Significant sedative effects of L-Asp $(F[1,19]=14.65, P<0.005)$ and $(+)-$ MK-801 $(F[1$, $19]=4.74, P<0.05)$ were detected. An interaction between L-Asp and $(+)-\mathrm{MK}-801$ was significant $(F[1,19]=5.58, P<0.05)$, suggesting that the suppressive effect of L-Asp on DVs was attenuated by the co-injection of $(+)-\mathrm{MK}-801$.

Table 1 shows the effect of i.c.v. injection of L-Asp with or without (+)-MK-801 on chicks undergoing social-isolation stress during the 10-min behavioral observation period in terms of various behavioral categories. Significant effects of L-Asp $(F[1,19]=$ $34.00, P<0.0001)$ and $(+)-$ MK-801 $(F[1,19]=7.00, P<0.05)$ were detected on active wakefulness. L-Asp also showed significant effect $(F[1,19]=9.95, P<0.01)$ on standing/sitting motionless with eyes open. In addition, significant effects of L-Asp $(F[1,19]=16.06$, $P<0.001)$ and $(+)-$ MK-801 $(F[1,19]=8.74, P<0.01)$ on sitting motionless with head drooped (sleeping posture) were detected. Interactions between L-Asp and (+)-MK-801 were significant in the following categories: active wakefulness $(F[1,19]=7.43, P<0.05)$; and sitting motionless with head drooped (sleeping posture) 
$(F[1,19]=6.49, P<0.05)$ - representing the sedative effect and the hypnotic effect, respectively. L-Asp increased sitting motionless with head drooped (the sleeping posture) and decreased active wakefulness, and (+)-MK-801 attenuated these effects. Since $(+)-$ MK-801 did not affect the behavioral categories under the control conditions, these results indicate that $(+)-\mathrm{MK}-801$ altered behaviors induced by L-Asp. The sleeping posture induced by L-Asp was attenuated by co-injection with (+)-MK-801, and consequently the behavior of chicks tended toward wakefulness.

\subsection{Effects of $(+)-M K-801$ on sedative and hypnotic behaviors induced by $D$-Asp}

Fig. 2 shows the effects of i.c.v. injection of D-Asp with or without $(+)-M K-801$ on the number of DVs for 10 min postinjection. A significant effect of D-Asp $(F[1,18]=48.14, P<0.0001)$ was detected, but no significant effect was observed with (+)-MK$801(F[1,18]=1.09, P>0.05)$. The lack of a significant $(F[1,18]=$ $1.09, P>0.05)$ interaction between D-Asp and $(+)-$ MK-801 implies that the effect of D-Asp was not attenuated by (+)-MK-801.

Table 2 shows the effect of i.c.v. injection of D-Asp with or without $(+)-\mathrm{MK}-801$ on chicks experiencing social-isolation stress during the 10-min behavioral observation period in terms of various behavioral categories. D-Asp showed significant effect on active wakefulness $(F[1,19]=28.62, P<0.0001)$ and standing/ sitting motionless with eyes open $(F[1,19]=5.07, P<0.05)$. In addition, significant effects of D-Asp $(F[1,19]=28.81, P<0.0001)$

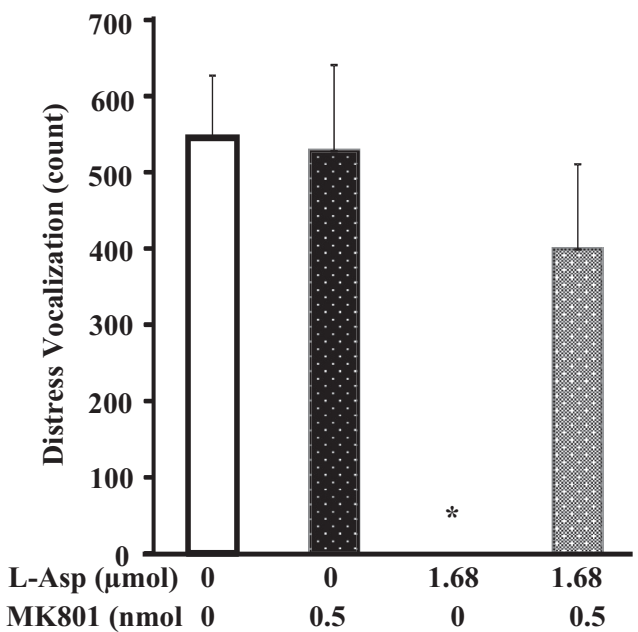

Fig. 1. Effects of i.c.v. injection of saline, (+)-MK-801 maleate $(0.50 \mathrm{nmol})$, L-Asp $(1.68 \mu \mathrm{mol})$ or L-Asp $(1.68 \mu \mathrm{mol})$ plus $(+)-\mathrm{MK}-801$ maleate $(0.50 \mathrm{nmol})$ on total number of distress vocalizations during $10 \mathrm{~min}$ of isolation in 5-6-day-old layer chicks ( $n=5$ or 6 ). Results are expressed as means \pm S.E.M. *Significantly different from other treatments at $P<0.05$. and $(+)-M K-801(F[1,19]=6.23, P<0.05)$ on sitting motionless with head drooped (sleeping posture) were detected. Interactions between D-Asp and (+)-MK-801 were significant in the following categories: standing/sitting motionless with eyes open $(F[1,19]=$ $6.35, P<0.05$ ); and sitting motionless with head drooped (sleeping posture $)(F[1,19]=7.97, P<0.05)$. These results indicate that (+)-MK-801 altered behaviors induced by D-Asp. Co-injection of D-Asp and (+)-MK-801 partially attenuated standing/sitting motionless with eyes open and, interestingly, induced the sleeping posture, a hypnotic behavior.

\section{Discussion}

We confirmed that i.c.v. injection of L-Asp can attenuate the stress responses under an acutely stressful isolation condition (Fig. 1, Table 1). L-Asp is most likely a neurotransmitter that mimics the actions of L-Glu (Kubrusly et al., 1998). Recently, our laboratory found that i.c.v. administration of L-Glu attenuated total DVs and induced sedation in chicks (Yamane et al., 2009b). L-Asp caused sedative and hypnotic effects under acutely stressful socialisolation conditions with or without i.c.v. injection of corticotrophinreleasing factor (CRF) (Yamane et al., 2009a; Erwan et al., 2012). It was further reported that the amount of L-Asp decreased in the diencephalon of neonatal chicks exposed to both restraint with isolation and fasting stress, indicating that L-Asp may be related to the stress response (Hamasu et al., 2009). L-Asp appears to act as a selective NMDA receptor agonist in chicks (Kubrusly et al., 1998) and mammals (Patneau and Mayer, 1990). In terms of the mechanism

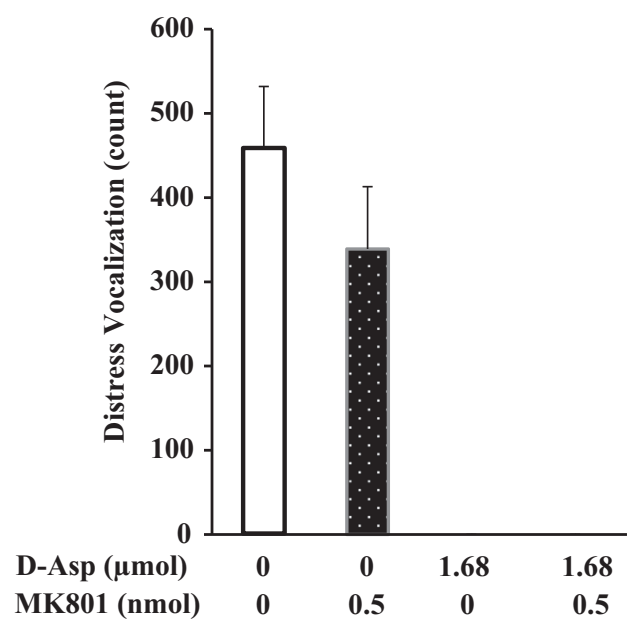

Fig. 2. Effects of i.c.v. injection of saline, $(+)-\mathrm{MK}-801$ maleate $(0.50 \mathrm{nmol})$, D-Asp $(1.68 \mu \mathrm{mol})$ or D-Asp $(1.68 \mu \mathrm{mol})$ plus $(+)-\mathrm{MK}-801$ maleate $(0.50 \mathrm{nmol})$ on total number of distress vocalizations during $10 \mathrm{~min}$ of isolation in 5-6-day-old layer chicks ( $n=5$ or 6 ). Results are expressed as means \pm S.E.M.

Table 1

Effects of i.c.v. injection of $(+)-$ MK-801 and L-aspartate on various behavioral categories of chicks exposed to social separation stress for 10 min.

\begin{tabular}{|c|c|c|c|c|c|c|c|}
\hline \multirow[b]{2}{*}{$(+)-\mathrm{MK}-801$} & \multicolumn{2}{|l|}{ Saline } & \multicolumn{2}{|c|}{ L-Aspartate } & \multicolumn{3}{|l|}{$P$} \\
\hline & - & + & - & + & L-Aspartate & $(+)-\mathrm{MK}-801$ & L-Aspartate $\times(+)-\mathrm{MK}-801$ \\
\hline Active wakefulness & $458 \pm 45^{\mathrm{b}}$ & $454 \pm 70^{\mathrm{b}}$ & $47 \pm 14^{\mathrm{a}}$ & $304 \pm 53^{\mathrm{b}}$ & $<0.0001$ & $<0.05$ & $<0.05$ \\
\hline Standing/sitting motionless with eyes open & $111 \pm 37$ & $129 \pm 59$ & $295 \pm 38$ & $228 \pm 46$ & $<0.01$ & NS & NS \\
\hline Standing motionless with eyes closed & $0 \pm 0$ & $0 \pm 0$ & $0 \pm 0$ & $0 \pm 0$ & NS & NS & NS \\
\hline Sitting motionless with head drooped (sleeping posture) & $31 \pm 21^{\mathrm{b}}$ & $17 \pm 17^{b}$ & $258 \pm 47^{a}$ & $68 \pm 39^{b}$ & $<0.001$ & $<0.01$ & $<0.05$ \\
\hline Total (s) & 600 & 600 & 600 & 600 & & & \\
\hline
\end{tabular}

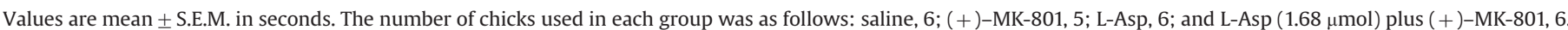
NS, not significant. Means with different superscripts are significantly different at $P<0.05$. 
Table 2

Effects of i.c.v. injection of (+)-MK-801 and D-aspartate on various behavioral categories of chicks exposed to social separation stress for 10 min.

\begin{tabular}{|c|c|c|c|c|c|c|c|}
\hline \multirow[b]{2}{*}{$(+)-\mathrm{MK}-801$} & \multicolumn{2}{|l|}{ Saline } & \multicolumn{2}{|c|}{ D-Aspartate } & \multicolumn{3}{|l|}{$P$} \\
\hline & - & + & - & + & D-Aspartate & $(+)-\mathrm{MK}-801$ & D-Aspartate $\times(+)-$ MK-801 \\
\hline Active wakefulness & $416 \pm 80$ & $351 \pm 92$ & $51 \pm 20$ & $61 \pm 19$ & $<0.0001$ & NS & NS \\
\hline Standing/sitting motionless with eyes open & $144 \pm 57^{\mathrm{b}}$ & $221 \pm 76^{\mathrm{b}}$ & $413 \pm 34^{\mathrm{a}}$ & $205 \pm 56^{\mathrm{ab}}$ & $<0.05$ & NS & $<0.05$ \\
\hline Standing motionless with eyes closed & $0 \pm 0$ & $0 \pm \overline{0}$ & $0 \pm \overline{0}$ & $0 \pm 0$ & NS & NS & NS \\
\hline Sitting motionless with head drooped (sleeping posture) & $40 \pm 26^{\mathrm{b}}$ & $28 \pm 21^{\mathrm{b}}$ & $136 \pm 17^{b}$ & $334 \pm 59^{a}$ & $<0.0001$ & $<0.05$ & $<0.05$ \\
\hline Total $(\mathrm{s})$ & 600 & 600 & 600 & 600 & & & \\
\hline
\end{tabular}

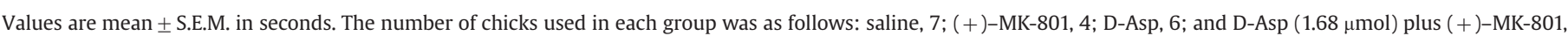
6. Groups with different superscripts are significantly different $(P<0.05)$. NS, not significant. Means with different superscripts were significantly different at $P<0.05$.

involved, in the current study we revealed that the sedative and hypnotic effects of L-Asp are mediated via the NMDA receptor since the sedative and hypnotic effects induced by L-Asp were negated by its antagonist, (+)-MK-801. The i.c.v. injection of $0.5 \mathrm{nmol}$ of MK-801 alone did not influence isolation stress-induced behaviors. These results indicate that the NMDA receptor is involved in sedative and hypnotic effects induced by L-Asp.

Many findings have indicated that D-amino acids may act as a putative neuromodulator or neurotransmitter (Schell et al., 1997; Errico et al., 2008a, b). In the current study, it was confirmed that i.c.v. injection of D-Asp could attenuate the stress response induced by isolation stress. The mechanism of the sedative effect of D-Asp was further revealed in neonatal chicks. It was clearly observed that i.c.v. injection of D-Asp strongly decreased DVs and active wakefulness (Fig. 2, Table 2). In addition, in comparison with the control group, D-Asp increased the amount of time spent standing/sitting motionless with eyes open. This finding is also consistent with our previous report (Erwan et al., 2012). It was further found that co-injection of D-Asp with (+)-MK-801 did not totally revive the DVs that were attenuated by the D-Asp (Fig. 2). This was the case also for the active wakefulness behavior: the active wakefulness that was decreased by administration of D-Asp was not restored when D-Asp was co-injected with (+)-MK-801. However, the amount of time spent standing/sitting motionless with eyes open was reduced when D-Asp was co-injected with $(+)-M K-801$. These results suggest that some stress-attenuating functions of D-Asp may occur through other receptor(s) besides the NMDA receptor. Until recently, the selective receptor for D-Asp had not been precisely identified (Carlson and Fieber, 2011; Ota et al., 2012). Although D-Asp is presumed to be activated as a subset of the L-Glu channels, the identities of the putative D-Asp receptors and channels are unclear (Carlson and Fieber, 2011). It has been reported that D-Asp activated the same receptor that L-Glu did, but D-Asp also activated other receptors in many cells which were not responding to L-Glu (Carlson et al., 2012). Furthermore, D-Asp is a well-known activator of the NMDA receptor, but conceivably D-Asp may also act as a neurotransmitter for other receptors (Gong et al., 2005; Brown et al., 2007; Carlson and Fieber, 2011). Hamasu et al. (2010) showed that L-and D-Pro differentially induced sedative and hypnotic effects through the NMDA receptor and the glycine receptor, respectively. Thus, the two isomers of Asp may activate different receptors to induce its function of attenuating stress. Interestingly, hypnotic effects were strongly induced by the combination of D-Asp and (+)-MK-801. In blocking the NMDA receptor, D-Asp showed a similar effect to that of L-Asp itself. This may be through unidentified receptors stimulated by D-Asp. This possibility should to be clarified in future studies.

It has further been reported that the metabotropic glutamate (mGlu) receptor 5 is linked to the NMDA receptor (Tu et al., 1999), supporting the interaction between these two receptor types (Awad et al., 2000; Pisani et al., 2001). Molinaro et al. (2010) suggested that D-Asp, but not L-Asp, activated the mGlu receptor 5 in the early postnatal rat brain. The mGlu receptor 5 could play various roles in the stress response because stress-induced hyperthermia was reduced in mGlu receptor 5 knockout mice (Brodkin et al., 2002). Furthermore, it was reported that the mGlu receptor 5 was involved in stress responsiveness in mammals (Brodkin et al., 2002). Matosin and Newell (2013) described that the mGlu receptor 5 was altered in response to NMDA receptor antagonist treatment in adult rats. Thus, we could speculate that in the current study, a possible alteration in the coupling between the NMDA receptor and the mGlu receptor 5 may have occurred when the NMDA receptor blocker, MK-801, was used to induce hypnotic behavior in chicks. These facts indicate that D-Asp may act through the NMDA receptor, including the mGlu receptor 5 , to induce the anti-stress function. On the other hand, kynurenic acid, one of the tryptophan metabolites in the kynurenine pathway, functioned via the simultaneous inhibition of the NMDA receptor subgroup and the $\alpha 7$ nicotinic acetylcholine receptor (Yoshida et al., 2013). It is possible that D-Asp simultaneously induces NMDA receptor and other receptors. Further research is needed to clarify the possible mechanism of the D-Asp function in chicks.

\section{Conclusions}

In conclusion, i.c.v. administration of both L- and D-Asp induced sedative effects under an acutely stressful condition. The mechanism of the attenuation of the acute stress response by L-Asp is mediated through the NMDA receptor in the CNS, while D-Asp may be involved with other receptors besides the NMDA receptor in attenuating stress behaviors in chicks. Overall, our data imply important roles of L- and D-Asp in reducing stress behavior in chicks which may lead to important benefits in interdisciplinary study.

\section{Acknowledgments}

This work was supported by a Grant-in-Aid for Scientific Research (No.23248046 to MF) from The Japan Society for the Promotion of Science. EE would like to thank the Directorate General of Higher Education (DGHE) of Indonesia for supporting a scholarship for this study.

\section{References}

Awad, H., Hubert, G.W., Smith, Y., Levey, A.I., Conn, P.J., 2000. Activation of metabotropic glutamate receptor 5 has direct excitatory effects and potentiates NMDA receptor currents in neurons of the subthalamic nucleus. J. Neurosci. 20 7871-7879.

Balázs, D., Csillag, A., Gerber, G., 2012. L-aspartate effects on single neurons and interactions with glutamate in striatal slice preparation from chicken brain. Brain Res. 1474, 1-7. 
Brodkin, J., Bradbury, M., Busse, C., Warren, N., Bristow, L.J., Varney, M.A., 2002. Reduced stress-induced hyperthermia in mGluR5 knockout mice. Eur. J. Neurosci. 16, 2241-2244.

Brown, E.R., Piscopo, S., Chun, J.T., Francone, M., Mirabile, I., D'Aniello, A., 2007. Modulation of an AMPA-like glutamate receptor (SqGluR) gating by L- and Daspartic acids. Amino Acids 32, 53-57.

Carlson, S.L., Fieber, L.A., 2011. Physiological evidence that D-aspartate activates a current distinct from ionotropic glutamate receptor currents in Aplysia californica neurons. J. Neurophysiol. 106, 1629-1636.

Carlson, S.L., Kempsell, A.T., Fieber, L.A., 2012. Pharmacological evidence that Daspartate activates a current distinct from ionotropic glutamate receptor currents in Aplysia californica. Brain Behav. 2, 391-401.

Chen, P.E., Geballe, M.T., Stansfeld, P.J., Johnston, A.R., Yuan, H., Jacob, A.L., Snyder, J P., Traynelis, S.F., Wyllie, D.J., 2005. Structural features of glutamate binding site in recombinant NR1/NR2A N-Methyl-D-Aspartate receptors determined by site-directed mutagenesis and molecular modeling. Mol. Pharmacol. 67, $1470-1484$.

Cotman, C., Monaghan, D., 1989. Multiple excitatory amino acid receptor regulation of intracellular $\mathrm{Ca} 2+$. Implications for aging and Alzheimer's disease. Ann. N.Y. Acad. Sci. 568, 138-148.

D'Aniello, A., 2007. D-Aspartic acid: an endogenous amino acid with an important neuroendocrine role. Brain Res. Rev. 53, 215-234.

Davis, J.L., Masuoka, D.T., Gerbrandt, L.K., Cherkin, A., 1979. Autoradiographic distribution of L-proline in chicks after intracerebral injection. Physiol. Behav. 22, 693-695.

Errico, F., Rossi, S., Napolitano, F., Catuogno, V., Topo, E., Fisone, G., D’Aniello, A., Centonze, D., Usiello, A., 2008a. D-aspartate prevents corticostriatal long-term depression and attenuates schizophrenia-like symptoms induced by amphetamine and MK-801. J. Neurosci. 41, 10404-10414.

Errico, F., Nistico‘, R., Palma, G., Federici, M., Affuso, A., Brilli, E., Topo, E., Centonze, D., Bernardi, G., Bozzi, Y., D’Aniello, A., Di Lauro, R., Mercuri, N.B., Usiello, A. 2008b. Increased levels of D-aspartate in the hippocampus enhance LTP but do not facilitate cognitive flexibility. Mol. Cell. Neurosci. 37, 236-246.

Erwan, E., Tomonaga, S., Yoshida, J., Nagasawa, M., Ogino, Y., Denbow, D.M., Furuse, M., 2012. Central administration of L- and D-aspartate attenuates stress behaviors by social isolation and CRF in neonatal chicks. Amino Acids 43, 1969-1976.

Erwan, E., Tomonaga, S., Ohmori, T., Mutaguchi, Y., Ohshima, T., Nagasawa, M., Yasuo, S., Tamura, Y., Furuse, M., 2013a. Oral administration of D-aspartate, but not of L-aspartate, reduces food intake in chicks. J. Poult. Sci. 50, 164-171.

Erwan, E., Chowdhury, V.S., Ito, K., Furuse, M., 2013b. Lauroyl-L-aspartate decreased food intake and body temperature in neonatal chicks. Pharmacol. Biochem. Behav. 113, 7-11.

Feltenstein, M.W., Lambdin, L.C., Ganzera, M., Ranjith, H., Dharmaratne, W. Nanayakkara, N.P., Khan, I.A., Sufka, K.J., 2003. Anxiolytic properties of Piper methysticum extract samples and fractions in the chick social-separation stress procedure. Phytother. Res. 17, 210-216.

Gong, X.Q., Frandsen, A., Lu, W.Y., Wan, Y., Zabek, R.L., Pickering, D.S., Bai, D., 2005. D-aspartate and NMDA, but not L-aspartate, block AMPA receptors in rat hippocampal neurons. Br. J. Pharmacol. 145, 449-459.

Halpain, S., Wieczorek, C.M., Rainbow, T.C., 1984. Localization of L-glutamate receptors in rat brain by quantitative autoradiography. J. Neurosci. 4, 2247-2258.

Hamasu, K., Haraguchi, T., Kabuki, Y., Adachi, N., Tomonaga, S., Sato, H., Denbow, D. M., Furuse, M., 2009. L-Proline is a sedative regulator of acute stress in the brain of neonatal chicks. Amino Acids 37, 377-382.

Hamasu, K., Shigemi, K., Tsuneyoshi, Y., Yamane, H., Sato, H., Denbow, D.M., Furuse, M., 2010. Intracerebroventricular injection of L-proline and D-proline induces sedative and hypnotic effects by different mechanisms under an acute stressful condition in chicks. Amino Acids 38, 57-64.

Koutoku, T., Takahashi, H., Tomonaga, S., Oikawa, D., Saito, S., Tachibana, T., Han, L., Hayamizu, K. Denbow, D.M. Furuse, M., 2005. Central administration of phosphatidylserine attenuates isolation stress-induced behavior in chicks. Neurochem. Int. 47, 183-189.
Koyuncuoğlu, H., Berkman, K., 1982. Effect of D- and/or L-aspartic acids on feeding, drinking, urine outflow and core temperature. Pharmacol. Biochem. Behav. 17 1265-1269.

Koyuncuoğlu, H., Berkman, K., Wildmann, J., Matthaei, H., 1982. Antagonistic effect of L-aspartic acid on decrease in body weight, and food and fluid intake, and naloxone reversible body temperature depression caused by D-aspartic acid. Pol. J. Pharmacol. Pharm. 34, 333-337.

Kubrusly, R.C., de Mello, M.C., de Mello, F.G., 1998. Aspartate as a selective NMDA receptor agonist in cultured cells from the avian retina. Neurochem. Int. 32 47-52.

Kurata, K., Shigemi, K., Tomonaga, S., Aoki, M., Morishita, K., Denbow, D.M., Furuse, M., 2011. L-Ornithine attenuates corticotrophin-releasingfactor-induced stress responses acting at GABAA receptors in neonatal chicks. Neuroscience 172 226-231.

Lindstrom, P., Ohlsson, L., 1992. Effect of N-methyl-D,L-aspartate on isolated rat somatotrophs. Endocrinology 13, 11903-11907.

Matosin, N., Newell, KA., 2013. Metabotropic glutamate receptor 5 in the pathology and treatment of schizophrenia. Neurosci. Biobehav. Rev. 37, 256-268.

Matthews, J.C., Hsu, C.H., Morris, K.R., 1991. Stimulation of $22 \mathrm{Na}+$ efflux from rat forebrain membrane vesicles by L-glutamic acid, L-aspartic acid and kainic acid. Biochem. Pharmacol. 42, 1811-1819.

Molinaro, G., Pietracupa, S., Di Menna, L., Pescatori, L., Usiello, A., Battaglia, G. Nicoletti, F., Bruno, V., 2010. D-aspartate activates mGlu receptors coupled to polyphosphoinositide hydrolysis in neonate rat brain slices. Neurosci. Lett. 478 128-130.

Neidle, A., Dunlop, D.S., 1990. Developmental changes of free D-aspartic acid in the chicken embryo and in the neonatal rat. Life Sci. 46, 1517-1522.

Ota, N., Shi, T., Sweedler, J.V., 2012. D-Aspartate acts as a signaling molecule in nervous and neuroendocrine systems. Amino Acids 43, 1873-1886.

Patneau, D.K., Mayer, M.L., 1990. Structure-activity relationships for amino acid transmitter candidates acting at N-methyl-D- aspartate and quisqualate receptors. J. Neurosci. 10, 2385-2399.

Pisani, A., Gubellini, P., Bonsi, P., Conquet, F., Picconi, B., Centonze, D., Bernardi, G., Calabresi, P., 2001. Metabotropic glutamate receptor 5 mediates the potentiation of $\mathrm{N}$-methyl-D-aspartate responses in medium spiny striatal neurons. Neuroscience 106, 579-587.

Schell, M.J., Cooper, O.B., Snyder, S.H., 1997. D-aspartate localizations imply neuronal and neuroendocrine roles. Proc. Natl. Acad. Sci. U. S. A. 94, 2013-2018

Shigemi, K., Tsuneyoshi, Y., Hamasu, K., Han, L., Hayamizu, K., Denbow, D.M., Furuse, M., 2008. L-Serine induces sedative and hypnotic effects acting at GABA (A) receptors in neonatal chicks. Eur. J. Pharmacol. 599, 86-90.

Suenaga, R., Tomonaga, S., Yamane, H., Kurauchi, I., Tsuneyoshi, Y., Sato, H., Denbow, D.M., Furuse, M., 2008. Intracerebroventricular injection of L-arginine induces sedative and hypnotic effects under an acute stress in neonatal chicks. Amino Acids 35, 139-146.

Tu, J.C., Xiao, B., Naisbitt, S., Yuan, J.P., Petralia, R.S., Brakeman, P., Doan, A., Aakalu, V. K., Lanahan, A.A., Sheng, M., Worley, P.F., 1999. Coupling of mGluR/Homer and PSD-95 complexes by the Shank family of postsynaptic density proteins. Neuron 23, 583-592.

van Luijtelaar, E.L., van der Grinten, C.P., Blokhuis, H.J., Coenen, A.M., 1987. Sleep in the domestic hen (Gallus domesticus). Physiol. Behav. 41, 409-414.

Yamane, H., Asechi, M., Tsuneyoshi, Y., Kurauchi, I., Denbow, D.M., Furuse, M., 2009a. Intracerebroventricular injection of L-aspartic acid and L-asparagine induces sedative effects under an acute stressful condition in neonatal chicks. Anim. Sci. J. 80, 286-290.

Yamane, H., Tsuneyoshi, Y., Denbow, D.M., Furuse, M., 2009b. N-methyl-D-aspartate and alpha-amino-3-hydroxy-5-methyl-4-isoxazolepropionate receptors involved in the induction of sedative effects under an acute stress in neonatal chicks. Amino Acids 37, 733-739.

Yoshida, J., Shigemura, A., Ogino, Y., Denbow, D.M., Furuse, M., 2013. Two receptors are involved in the central functions of kynurenic acid under an acute stress in neonatal chicks. Neuroscience 248, 194-200. 